\title{
EAMR
}

European Accounting and

Management Review

EUROPEAN ACCOUNTING AND MANAGEMENT REVIEW · VOL. 2, NO. 2, 42-55 MAY 2016

\section{The OPTIMAL MBO: A model for effective management-by- objectives implementation}

\author{
Sharon Gotteiner \\ Universitat Internacional de Catalunya
}

Received March 18, 2015; accepted May 23, 2016.

\begin{abstract}
The Management-by-Objectives (MBO) approach is wide spread, but has been challenged to demonstrate its consistent, positive effect on organizations' performance. The OPTIMAL MBO is a revised formula, proposed for vitalizing the original MBO approach. It includes some additional components related to business strategy, financial performance, and incentives, as well as some tune-ups to existing components, and aims at wining executive support. The OPTIMAL MBO stands for its integrated set of components, namely: (O) Objectives, Outside-in; (P) Profitability (budget) related goals; (T) Target Setting; (I) Incentives \& Influence; (M) Measurement; (A) Agreement, Accountability, Appraisal, Appreciation; and (L) Leadership Support. Empirical testing of impact on operational and financial performance is called for.
\end{abstract}

\section{KEYWORDS}

Leadership, management, management-by-objectives, MBO, performance. 


\section{Introduction}

Management by objectives (MBO) studies indicate that the implementation of this approach has become wide spread over the past three decades, in both private and public sectors, and that most corporations use it (Rodgers \& Hunter, 1991). The percentage of Fortune 1000 companies using MBO nearly tripled from 27 percent in 1981 to 79 percent in 2008 (Curtin, 2009). Notwithstanding its widespread use, MBO has struggled to prove its effectiveness, without much success. Studies examining the effectiveness of MBO indicated that the impact of MBO generated mixed results, and raised questions about the circumstances under which it is effective (Kondrasuk, 1981), as such pointing at the contingency approach. Indeed, 68 studies out of 70 showed productivity gains, and only 2 studies showed losses (Rodgers \& Hunter, 1991). But even when positive effects were reported, such effects did not measure the improvement in a firm's financial performance (Thompson et al., 1981). Substantial attention had been focused on the reported failures of MBO as a management technique (Scott, 1980; Duffy, 1989), and the search for the ideal MBO formula has proved to be as futile as the search for the best leadership style (Muczyk \& Reimann, 1989). Some researchers were led to consider MBO as an outdated management fad (Roth, 1999).

And yet, it seems that giving up on MBO is uneasy to digest; The three major components of $\mathrm{MBO}$, namely goal setting, participation in decision making, and objective feedback, are separately and together as a system, shown to yield increases in organizational productivity. If goal setting alone works, why doesn't the whole MBO system work? (Kondrasuk, 1981). The gap between the consensus over goal-setting effectiveness, and the actual MBO performance - is too loud to ignore and move on from.

The objective of this study is to revitalize the MBO approach, by proposing a formula that could fix it, and make it an effective tool in driving financial performance. It first reviews the MBO approach's performance challenge as a whole, and the various components of $\mathrm{MBO}$ and their flaws, as identified by prior researchers. It then turns to the corporate restructuring and turnaround research and literature in search of practices which could fix such flaws, for turnaround companies live the MBO dream. Such companies are often ill-disciplined, and lack any sense of a performance-oriented culture (Slatter et al., 2006: p. 15). At the time of a turnaround, success has to be clearly defined, so it can be translated into goals, complete with targets and the right metrics to measure them by (Roman, 2010: p. 234). Following, is an integration of MBO components with turnaround practices, aiming at forming a grafted, improved formula, whose impact on 
organizational operational and financial performance could be empirically tested by future research.

\section{Literature Review}

\subsection{MBO Challenges}

Researchers suggested various factors as contributors to the failure of $\mathrm{MBO}$. The failure was attributed to the variety of definitions for that term, and confusion around its meaning (Kondrasuk, 1981), multiple variations or other problems in MBO's implementation process (Rodgers \& Hunter, 1991), lack of appropriate incentive systems, top management support, or inadequate training (Muczyk \& Reimann, 1989), the introduction of $\mathrm{MBO}$ into organizations without considering its viability and appropriateness (Duffy, 1989), and the decadence of the hierarchical model, which did not fit the new-era management, calling for higher degrees of participative management and innovation (Roth, 1999). These contributors to the failure of MBO are elaborated hereby and analyzed from a corporate turnaround and restructuring perspective.

\subsection{Objectives, Outside-in}

MBO calls organizations to define their objectives, in order to support organized work on their attainment. Such objectives should be defined in a practical manner, to allow conversion into clear, measurable goals, then targets, and then measurements down the road. That should prevent the confusion between motion and performance, or between knowledge and action. However, confusion is not always avoided: One of the central problems of $\mathrm{MBO}$ is the tendency to direct efforts and vision towards inside processes, rather than towards the purpose on the outside (Drucker, 1976).

Drucker's observation reconciles with the approach applied as a part of an "Outside-in Turnaround", which involves stepping outside the boundaries and constraints of the company and looking at its market through the eyes of customers and competitors (Day and Moorman, 2013). It also reconciles with the observation that MBO may get fixed by aligning it with the planning / marketing process, and specifically with its strategic phase, an area in which MBO is failing (Duffy, 1989). The strategic phase of the planning / marketing process is concerned with an organization's long-term considerations, including its opportunities, business strategy, positioning strategy, mission statement, and 
marketing systems. Of those, the mission statement can serve as the kind of strategic "compass" for keeping organizational objectives on a strategic track: The management literature suggests that carefully prepared mission statements are widely recognized by both practitioners and academicians as the first step in strategic management, and as an essential tool for effectively establishing objectives (David et al. 2014). Such a focal point for objectives may also prevent any one department from dominating the organizational objectives, an adverse symptom identified in turnaround firms (Scherrer, 1988).

As such it is proposed to make sure that an organization's objectives are focused on the outside, and specifically, aligned with its mission statement. Practically, that means identifying the link between the objectives set, and the main questions answered by a traditional mission statement, namely: What is our business? Who is the customer? What is the value to the customer? What will our business be? and What should our business be? (Kotler, 1980).

\subsection{Profitability (budget) related Goals}

Each area of objectives requires a number of separate goals to be set. In order for goals to be clear and measurable, they should include specific work assignments, specific timetables, specific strategies, and specific resources, especially manpower (Drucker, 1976). There is much experimental evidence that goal setting improves performance (Kondrasuk, 1981).

It is proposed that on top of the strategic goals set in light of strategic objectives, operating goals be set as well. Operating turnaround strategies play a key role in corporate turnaround and restructuring. Despite their name, such strategies aim at recovering from poor financial performance, and include strategies such as cost efficiencies and asset reduction. They are triggered by internal factors, such as poor management, inefficient cost-structure, non-optimal debt-structure, over expansion, or poor control-environment, and as such aim at fixing internal processes (Schendel et al., 1976; Hofer, 1980; Hambrick \& Schecter, 1983; Robbins \& Pearce, 1992; Arogyaswamy et al. 1995; Bibeault, 1999: 226-238; Safrudin et al, 2014). While corporate turnaround and restructuring address financial performance in terms of profitability, public-sector organizations may address the avoidance of a budget deficit. 
The distinction between strategic health and operating (financial) health is also borrowed from the turnaround literature and research. These two types of health represent different priorities and tradeoffs with short-term versus long-term recovery strategies (Hofer, 1980) Corporate health, or recovery, requires focus on both internal processes and the outside, in turn: The focus of operating turnarounds is reaching a sustainable level of reasonable profitability by fixing internal processes. As soon as profitability is reached, investment in strategic growth can, and should, be pursued (Arogyaswamy et al., 1995; Bibeault, 1999: p. 92, 237; Teng (2010) p. 42). The same tango is proposed for MBO.

\subsection{Target Setting}

Goals should be converted into specific targets (Drucker, 1976). Target setting plays a major role in turnarounds: It helps in recognizing success when we get there (Roman, 2010: p. 234). In fact, in looking for manpower reductions, managers are asked to determine if they can establish performance targets for each person on their staff (Bibeault, 1999: p. 249). What differs targets from goals is that target achievement is controllable at the individual employee level, and expected to be achieved. And finally, targets should be revisited periodically, in order to consider what worked and what didn't, and push the limits of success further (Roman, 2010: p. 190).

\subsection{Incentives \& Influence}

Lack of appropriate incentive-systems has contributed to the failure of MBO (Muczyk \& Reimann, 1989). That includes the lack of reward systems which are based on team and organization productivity as well as that of individuals, as called for by the "new era" team approach (Roth, 1999).

Corporate restructuring and turnaround literature calls for fighting the phenomenon of managers becoming non-achievers, and perceiving their role as simply defenders of status-quo. Performance-based rewards can help change such situations (Bibeault, 1999: p. 349). Changing reward systems - particularly bonus and incentive systems - is a key component in many turnaround strategies (Armenakis \& Fredenberger, 1995; Muczyk, 1998). The main point is to link rewards to key performance indicators measuring the performance of given processes, whether targeting sales, or operational productivity, or other (Slatter \& Lovett, 1999: p. 257; Slatter et al., 2006: p. 186). A prerequisite here is ability of an individual to influence such processes; setting incentives referring to targets 
which are beyond the individual's control, whether solely or as a team member, cannot be effective and may also deliver the wrong message.

Bonuses and incentives should be based on both individual and team performance, and should be paid monthly, as an integral part of the routine salary structure (Sutton, 2002: p. 111; Roman, 2010: p. 221). It is proposed to reinforce MBO by applying the same as a part of its implementation.

\subsection{Measurement}

MBO calls for directing effort and vision by measuring performance. That includes the definition of how performance can be measured, or at least judged. Unless results can be appraised objectively, there will be no results. There will only be activity, that is, costs. To produce results, it is necessary to know what results are desirable, and be able to determine whether the desired results are actually being achieved (Drucker, 1976). This approach is widely supported by corporate restructuring and turnaround researchers and practitioners (Bibeault, 1999: p. 235; Sutton, 2002; Roman, 2010: p. 187).

Arguments against MBO's call for measuring performance were related to its focus on the individual, namely: that such a focus on the individual does not capture how well team members work collectively, and; that measuring individuals' performance is becoming increasingly difficult, as organizations grow more complex and responsibilities grow more interdependent (Roth, 1999). Indeed, corporate restructuring and turnaround practitioners call for measurements which capture both group and individual performance. It is advised that goals shared by relevant managers and teams prevent conflicts between owners across the company (Roman, 2010: p. 198). It is also advised that incentives be designed to support cross-company (unit) team-work and peer-pressure, and prevent the creation of lone-wolves (Sutton, 2002: p. 111). The challenge of measuring individuals' performance has not been identified by corporate restructuring and turnaround practitioners, as an obstacle. In fact, practice calls for responding to individuals' performance, through either performance-based rewards, further job training, or disciplinary measures, where necessary (Bibeault, 1999: p. 349). As such, it is proposed that both group and individual performance be measured. 


\subsection{Agreement, Accountability, Appraisal, Appreciation}

MBO calls for obtaining an understanding and agreement within the organization over: the organization's objectives and their balance; goals and strategies; priorities and abandonment of un-prioritized goals; efforts and resource allocation; and measurements. The individual manager is asked to describe how his goals, priorities, and strategies, can support those of the organization (Drucker, 1976). Denison (1984) provided hard evidence that companies with a participative attitude towards members, in the sense of achieving high levels of shared meaning, normative integration, and a common vision, reap a return on investment (ROI) that averages nearly twice as high as those in firms who are not. At the same time, Denison observed that organizational culture must also fit its business environment. On top of the positive psychological effect of such inclusion, the positive effect was explained by an operational one as well: with participatory input from lower levels, useful information that is known to subordinates is made known to top management (Rodgers \& Hunter, 1991).

Over the years, multiple variations of alleged MBO evolved, proposing a wider range of participation levels. Some of those were described as highly participative and permissive (Muczyk \& Reimann, 1989). It came to a point where it had to be clarified that MBO could work, if it were modified to function within the planning/marketing process, and as a part of it, rather than aiming at replacing it (Duffy, 1989). Simultaneously, MBO was losing top-management support where organizations and leaders did not incline to be participative or permissive. It has been realized that it makes more sense to switch to another brand of MBO rather than try to change the organization and its leaders (Muczyk \& Reimann, 1989).

Drucker (1976) identified the problem of MBO getting out of control, in real time, and clarified: "The advocate of MBO likes to talk about participation. This is a misleading term, or at least an inadequate term. The desired result is willingness of the individual within the organization to focus his or her own vision and efforts towards the attainment of the organization's goals... The desired result is commitment, rather than participation." However, that was too late. The meaning of MBO had already been misunderstood, it had been wrongly implemented, and was soon pronounced as a failure, as described above. But apparently, the failure should have been more accurately attributed to the Participation component (Heckscher, 1995).

The turnaround literature relates to individuals' willingness to focus their efforts towards the attainment of the organization's goals, as called for by the original MBO. It is often 
found that employees do not associate their own goals with the goals of the business in which they work. To recover, it is important that employees develop a proprietary interest in the business and feel that if it succeeds, they will succeed (Bibeault, 1999: p. 195). All department leaders should sign with the organizational goals (Roman, 2010: p. 198). And at the same time, managers should handle the soft issues and win the hearts and commitment of the staff (Armenakis \& Fredenberger, 1995). Unless these are addressed, the financial number will inevitably be brought down (Midanek, 2008; Teng, 2010: p. 154). That may be the accurate balance between organizational goals and participation: all employees must get in line with the organizational goals that percolate down the chain of command. But in order for that process to be effective, i.e. positively affect the financial numbers, managers should involve their reports in decision making, and in setting personal goals that serve the organization, and win their hearts and commitment, without undermining their own authority. That is also the exact mix proposed for a recovered MBO approach.

Accountability is another component of MBO. It aims at producing responsibility and commitment for performance and results within the organization, and making self-control possible on the part of the managerial and professional staff (Drucker, 1976).

Implementing accountability is a major task in turnaround companies too; In most of such firms, managers and employees have not been held accountable for results, and making them accountable for meeting budgets, targets, deadlines, etc., is the first step in building a performance or results-oriented culture (Scherrer, 1988). Accountability starts to have traction only when senior management is seen to deal with poor performance by removing individuals from their jobs (Slatter et al., 2006: p. 186). Every job should be pinpointed with ownership and accountability (Sutton, 2002: p. 124).

As such, it is proposed that the accountability be enforced as a part of the MBO. Individuals should be expected to perform, and non-performers should expect low levels of tolerance, rather than acceptance.

Organized, objective appraisal is supported by measurable goals to which the MBO participant committed (Drucker, 1976). That is common for turnaround companies as well (Armenakis \& Fredenberger, 1995). In fact, delegation of authority (influence) without inspection, control, feedback, or reinforcement, is one of the early signs of a crisis (Scherrer, 1988). As far as employees are performing, the turnaround literature emphasizes the importance of public appreciation of notable achievements, beyond the 
two-way appraisal communication between a manager and his or her subordinate (Sutton, 2002: p. 111; Midanek ,2008). The same is proposed for MBO.

\subsection{Leadership Support}

Lack of top management support has contributed to the failure of MBO (Muczyk \& Reimann, 1989). When top-management commitment was high, the average gain in productivity was found to be $56 \%$, comparing to $6 \%$ when it was low (Rodgers \& Hunter, 1991). As such the question is, why has MBO failed to attain top-management support? Duffy (1999) provides a lead: MBO can be successfully implemented where top management support is strong, where decision-making is centralized, and where decisions are of an analytical nature. All together, these findings lead to speculate that MBO could have gotten top-management support, and succeeded, if it didn't undermine the centralized decision making, and if it led to decisions of a more analytical nature.

But as observed earlier, MBO may have called for a level of participation / understanding / empowerment which was too difficult for traditional, hierarchical management to swallow and support. In addition, it lacked the financial-operational goal setting and focus, top-management is concerned about on a quarterly basis. In combination, that may have resulted in a more hectic, participative environment, where the voice of less experienced and unaccountable layers had to be heard, without that helping to meet the next quarter's financial forecast. No wonder that attaining leadership support was a challenge. When that is missing, leading by example is not applicable, and the whole approach cannot be enforced (Guiso et al., 2013). If the components described so far were absorbed into the MBO approach, it could have made a difference in the levels of leadership support attained. 


\section{Conclusion}

Although MBO is wide spread as a managerial approach, it did not manage to demonstrate its positive effect on organizations' performance, and particularly on their ability to achieve their strategic and financial goals. This study aims at fixing the MBO approach, and making it an effective managerial tool. It proposes an enriched formula for MBO implementation, which includes additional elements borrowed from the field of corporate turnaround and restructuring, where improved performance is the key to survival.

Solving the riddle of $\mathrm{MBO}$ effectiveness and fixing it, if possible, will prevent throwing the baby out with the bathwater, and will provide a tool for improving organizations' performance. Such a tool may be handy in sustaining a healthy level of financial performance, or in achieving competitive advantage, or in recovering troubled firms.

Integration of the traditional $\mathrm{MBO}$ approach, with corporate turnaround and restructuring components, can actually form the OPTIMAL MBO approach, whose highlights are summarized in Table-1:

\begin{tabular}{|c|c|}
\hline Objectives, Outside-in & $\begin{array}{l}\text { Align objectives with the mission-statement. } \\
\text { Convert such objectives into clear goals. }\end{array}$ \\
\hline $\begin{array}{l}\text { Profitability (budget) } \\
\text { related Goals }\end{array}$ & $\begin{array}{l}\text { Add goals that aim at improved financial } \\
\text { performance. }\end{array}$ \\
\hline Target Setting & Convert goals into controllable targets. \\
\hline Incentives \& Influence & $\begin{array}{l}\text { Pay incentives as a part of the monthly } \\
\text { salary. Link it with team and individual targets. }\end{array}$ \\
\hline Measurement & $\begin{array}{l}\text { Maintain objective measurements of the } \\
\text { actual performance. }\end{array}$ \\
\hline $\begin{array}{l}\text { Agreement, Accountability, } \\
\text { Appraisal, Appreciation }\end{array}$ & $\begin{array}{l}\text { Attain Employees' commitment for their } \\
\text { targets, maintain periodical appraisals, respond } \\
\text { to the levels of actual performance. }\end{array}$ \\
\hline Leadership Support & $\begin{array}{l}\text { Following all the above should win executive } \\
\text { support. Executives should demonstrate such } \\
\text { support. }\end{array}$ \\
\hline
\end{tabular}

Table 1. OPTIMAL MBO Highlights 
Nevertheless, implementation of the OPTIMAL MBO, and particularly the emphasis given to each one of its elements, must take into account the specific characteristics of a given organization, and the legal environment in which it operates. For example, public sector organizations may replace profitability-related goals with budget and service levels related ones; Public sector organizations may also be required to replace monetary incentives with other forms of compensation or gratitude; dismissing employees for poor performance should be coordinated with Unions, where existing, or considered in light of applicable regulation; Striving for agreement over targets may not suit highly-hierarchical organizational cultures.

Effective implementation of the OPTIMAL MBO should keep its spirit, while balancing the emphasis of each one of its elements with the specific characteristics, environment, and performance challenges of a given organization. The following principles may reflect commonality of OPTIMAL MBO implementation:

Organizational objectives should be focused on the outside.

Objectives should be converted into clear, measurable goals, Financial goals should be set in addition to outside-oriented ones.

Goals should be converted into specific, controllable targets.

Individuals should be assigned with targets within their control, both solely and as team members.

Appropriate incentives should relate to the achievement of targets.

Results should be objectively measured, or at least judged.

Managers should lead their subordinates to commit to their targets.

Individuals should be held accountable for achieving their targets.

Periodical appraisals should monitor the achievement of targets.

Top performers should win echoing appreciation.

Non-performers should pay a price.

Leadership support is expected if all the above was followed.

If supported, executive commitment should be explicitly demonstrated. 
The OPTIMAL MBO model still lacks direct, empirical research support. I hope some of the readers will find it worth testing within their organizations, and provide case-studies to test the impact of OPTIMAL MBO on organizations' operational and financial performance. 


\section{REFERENCES}

Armenakis, A. A., \& Fredenberger, W. B. (1995). Process strategies for turnaround change agents: crisis and non-crisis situations. Journal of Strategic Change, 4(1), 19-31.

Arogyaswamy, K., Barker III, V.L. and Yasai-Ardekani, M., (1995). Firm Turnarounds: an Integrative Two-Stage Model. Journal of Management Studies, Vol. 32, Issue 4, pp.493-525.

Bibeault, D.B. (1999). Corporate Turnaround: How Managers Turn Losers into Winners! Beard Books, Washington, DC.

Bowen, D. E., \& Ostroff, C. (2004). Understanding HRM-Firm Performance Linkages: The Role of the 'Strength' of the HRM System. The Academy of Management Review, (2). 203.

Curtin, J. L. (2009). Values-Exchange Leadership: Using Management by Objectives Performance Appraisals to Improve Performance. Leadership Review, 9, 66-79.

David, M. E., David, F. R., \& David, F. R. (2014). Mission Statement Theory and Practice: A Content Analysis and New Direction. International Journal of Business, Marketing, \& Decision Science, 7(1), 95-110.

Day, G., \& Moorman, C. (2013). Regaining Customer Relevance: The Outside-in Turnaround. Strategy and Leadership, 41(4), 17-23.

Denison, D. R. (1984). Bringing Corporate Culture to the Bottom Line. Organizational Dynamics, 13(2), 5-22.

Drucker, P. F. (1976). What Results Should You Expect? A Users' Guide to MBO. Public Administration Review, (1).

Duffy, M. F. (1989). ZBB, MBO, PPB and their Effectiveness within the Planning/Marketing Process. Strategic Management Journal, 10(2), 163-173.

Guiso, L., Sapienza, P., \& Zingales, L. (2015). The value of Corporate Culture. Journal of Financial Economics, 117(NBER Conference on the Causes and Consequences of Corporate Culture), 60-76. doi:10.1016/j.jfineco.2014.05.010

Hambrick, D.C. and Schecter, S.M. (1983), Turnaround Strategies for Mature Industrial Product Business Units. Academy of Management journal, Vol. 26, pp. 231-248.

Heckscher, C. (1995). The Failure of Participatory Management. (cover story). Across The Board, 32(10), 16.

Hofer, C.W. (1980), “Turnaround Strategies”, Journal of Business Strategy, Vol. 1, pp. 19-31.

Kondrasuk, J. N. (1981). Studies in MBO Effectiveness. The Academy of Management Review, (3). 419. 
Kotler, P. (1980). Strategic Planning and the Marketing Process. Business, 2.

Midanek, D. H. (2008). Cultivating Companies: Growing Value Using Turnaround Management Techniques. Journal of Private Equity, 11(2), 19-23.

Muczyk, J. P., \& Steel, R. P. (1998). Leadership Style and the Turnaround Executive. Business Horizons, 41(2), 39.

Muczyk, J. P., \& Reimann, B. C. (1989). MBO as a Complement to Effective Leadership. The Academy of Management Executive (1987-1989), (2). 131.

Robbins, D.K. and Pearce, J.A. (1992). Turnaround: Retrenchment and Recovery. Strategic Management Journal, Vol. 13, pp. 287-309.

Rodgers, R., \& Hunter, J. E. (1991). Impact of Management by Objectives on Organizational Productivity. Journal of Applied Psychology, (2), 322. 